\title{
Evidências léxico-gramaticais de representações na voz de ativistas e de homossexuais idosos
}

\author{
Lexico-grammatical evidences of representations in the voice \\ of activists and elderly homosexuals
}

Thiago Santos da Silva

Cristiane Fuzer

Universidade Federal de Santa Maria

Resumo: $\mathrm{O}$ objetivo deste trabalho é analisar recursos linguísticos usados na construção de representações sobre homossexuais idosos manifestadas no discurso de ativistas e dos próprios gays idosos no contexto da mídia. A perspectiva teórica que embasa este estudo é a Linguística Sistêmico-Funcional (HALLIDAY e MATTHIESSEN, 2004), com foco no sistema de transitividade. O corpus se constitui de textos publicados de 2006 a $2010 \mathrm{em}$ diferentes fontes. A análise dos dados linguísticos evidenciou que os homossexuais idosos são representados ora como pessoas solitárias, vítimas de preconceito e sem políticas de proteção, ora como indivíduos que buscam no discurso quer dos representantes do discurso ativista quer dos próprios gays idosos no contexto da mídia em espaços homossexuais a fim de participar da luta pelos direitos LGBT.

Palavras-chave: Gramática Sistêmico-Funcional. Representação. Transitividade.

Abstract: Developed in the field of Applied Linguistics and Professional Practice (SARANGI, 2012), this paper investigates construction of the identity of the Head of the English Department focusing on evaluation. The theoretical framework is based on the

1. Trabalho resultante da pesquisa em nível de mestrado desenvolvida pelo primeiro autor e orientada pela segunda autora, vinculado ao projeto "Gramática Sistêmico-Funcional da língua portuguesa para análise de representações sociais” (GAP/CAL 025406, FUZER, 2009) 
concept of identity according to social constructionist theories (BUCHOLTZ; HALL, 2003, 2005) in the interface of Appraisal Theory (MARTIN; WHITE 2005; VIAN JR., 2009, 2012). The data was gathered in a qualitative research interview and results suggest that the use of evaluative and semantic resources of affect, judgment and appreciation lead to the identity of the Head in the target context.

Key-words: Identity. Evaluation.Head of the English Department.

Thiago Santos

da Silva

Cristiane Introdução

Fuzer
Com 66 anos, não dá para ser mocinho. Eu vou continuar sendo marginal (BAILÃO2 2009 )

A fala usada como epígrafe desta seção demonstra a posição social ocupada pelos homossexuais que se encontram na terceira idade, a marginalidade. Essa visão tem sido corroborada pelas ainda incipientes pesquisas que têm apresentado como objeto de estudo a relação entre homossexualidade e curso de vida. Esses estudos, como os desenvolvidos por Pocahy (2008), Correia (2009) e Mota (2009), têm mostrado que o corpo envelhecido, frequentemente dissociado de qualquer atributo erótico e estético, caracterizado como um corpo a-social, no caso dos homossexuais, é visto como duplamente desvalorizado, porque, além de trazer a representação supracitada atribuída a qualquer idoso, carrega uma sexualidade considerada dissidente (PAIVA, 2009). Assim, essa parcela da comunidade homossexual se encontra numa posição marginalizada, ou mais enfaticamente, como diz Paiva (2009, p. 5), localiza-se nas "margens mais distantes".

A partir dessa conjuntura sociocultural, neste trabalho, analisamos a linguagem usada para representar homossexuais idosos em textos jornalísticos da mídia eletrônica brasileira. Para isso, foi realizado, com base em princípios da Gramática Sistêmico-Funcional ${ }^{3}$ (doravante GSF) de Halliday e Matthiessen (2004), o estudo das funções léxico-gramati-

\footnotetext{
2. Curta-metragem dirigido pelo cineasta Marcelo Caetano que apresenta o depoimento de cinco personagens frequentadores do "ABC Bailão", um local de socialização de homossexuais sessentões no centro de São Paulo. O filme encontra-se disponível no site Porta Curtas Petrobrás (http://portacurtas.org.br/filme/?name=bailao).

3. Os sistemas léxico-gramaticais propostos pela Gramática Sistêmico-Funcional estão apresentados em língua portuguesa por Fuzer e Cabral (2014).
} 
cais do sistema de transitividade desempenhadas por itens lexicais que se referem a homossexuais idosos em 19 textos publicados na internet, no período de 2006 a 2010, focalizando representações manifestadas na voz dos próprios homossexuais idosos e na voz de ativistas.

Análises de funções léxico-gramaticais desempenhadas por referentes a atores sociais ou acontecimentos têm sido profícuas para evidenciar representações manifestadas em textos de língua portuguesa, situados em diversos contextos, dentre os quais destacamos alguns estudos prévios. No contexto da mídia brasileira, foram analisadas como funções léxico-gramaticais e semântico-discursivas evidenciam representações ora por ativação ora por passivação de participantes de reality shows em artigos de opinião publicados em jornais (FUZER, 2012) e também foram identificadas representações para a seleção brasileira

Evidências léxico-gramaticais de representações na voz de ativistas e de homossexuais idosos. de futebol em notícias sobre a Copa do Mundo de 2010 (FUZER; FACCIN, 2012). No contexto literário, foi verificado como escolhas linguísticas representam os personagens principais em fábulas e qual a relação dessas representações com os contextos de produção dos textos (FARENCENA; FUZER, 2011). No contexto jurídico, análises de aspectos do contexto mais amplo e da léxico-gramática forneceram evidências de representações dos atores sociais envolvidos na sentença condenatória referente ao caso Isabella Nardoni (FUZER, 2010).

Assim como esses estudos, dentre outros que sistematizam evidências linguísticas na construção de representações, este trabalho utiliza categorias da GSF (HALLIDAY; MATTHIESSEN, 2004), mais especificamente o sistema de transitividade, apresentadas na próxima seção. Em seguida, é descrita a metodologia empregada no estudo. Depois, é apresentada a análise dos dados obtidos nas vozes analisadas. Por fim, na última seção, estão as conclusões a que o estudo nos permitiu chegar.

\section{Oração como representação na GSF}

A Linguística Sistêmico-Funcional (LSF), cujos princípios têm por base a GSF desenvolvida por M. A. K. Halliday $(1985,1994)$ e revisada por Halliday e Matthiessen (2004), é caracterizada por Barbara e Macedo (2009) como uma teoria social, pois "parte da sociedade e da situação de uso para o estudo da linguagem" (p. 90). Nessa perspectiva linguística, a preocupação está em compreender como é estabelecida a interação entre as pessoas, tendo como ponto de partida o estudo do significado associado ao contexto de uso das formas linguísticas. A lin- 
Thiago Santos

da Silva

Cristiane

Fuzer

guagem é entendida como um sistema sociossemiótico que possibilita construir e interpretar significados em contexto sociais. Nesse sentido, a gramática é vista como um "sistema de escolhas possíveis não arbitrariamente motivadas, ainda que nem sempre consciente, uma vez que o grau de consciência pode variar de uma escolha subconsciente até uma escolha mais consciente" (DAMASCENO; RODRIGUES; NOBRE, 2014, p. 497).

Na teoria sistêmico-funcional, a linguagem, por ser um complexo sistema semiótico, está organizada em estratos, os quais, de acordo com Halliday e Matthiessen (2004), são organizados em uma escala de abstração. $O$ estrato menos abstrato é o da expressão, no qual se encontram a fonologia (sistema de sons) e a grafologia (sistema de escrita). Ambos realizam, no estrato do conteúdo, a léxico-gramática (sistema de fraseado), que, por sua vez, ainda no estrato do conteúdo, realiza a semântica (sistema de significados). Todos esses estratos realizam uma camada mais abstrata da escala da linguagem, o estrato contextual, que, segundo Halliday (1989), divide-se em dois contextos: o de situação e o de cultura. $O$ contexto de situação caracteriza-se por ser o ambiente imediato no qual um texto está efetivamente realizando um propósito. O contexto de cultura, por sua vez, está ligado a "aspectos socioculturais mais amplos da atividade humana" (MEURER, 2004, p. 134), ou seja, apresenta-se como um conjunto de experiências cujos significados são compartilhados.

Assim, por ser um aparato teórico-metodológico cujo objetivo é analisar a linguagem em funcionamento em determinado contexto, a teoria sistêmico-funcional considera que todo uso linguístico é pautado por escolhas feitas pelo falante dentre uma gama de possibilidades que o sistema da língua possui. o lugar em que as escolhas de significados são feitas é a oração, o centro de ação da gramática (WEBSTER, 2009). Na teoria hallidayana, a oração é entendida como um constructo léxico-gramatical multifuncional responsável por representar experiências (metafunção ideacional), garantir a troca entre os interlocutores (metafunção interpessoal) e organizar a mensagem (metafunção textual).

Tendo em vista que o objetivo deste trabalho é investigar representações manifestadas no estrato léxico-gramatical num conjunto de textos, dedicamo-nos ao estudo da função que permite ao falante representar as experiências. Para Halliday (1989), além de considerar a 
oração sob o ponto de vista da interação que o falante estabelece com seu interlocutor e do modo como a informação está organizada, a linguagem também possibilita que se diga algo sobre um determinado assunto, isto é, permite ao falante representar o mundo. Esse mundo representado pode se referir ao domínio externo, como coisas, eventos, qualidades, etc., e ao domínio interno, tal como crenças, pensamentos, sentimentos.

De acordo com Thompson (2004), ao se focalizar na capacidade da linguagem em representar experiências, está-se centrando no "conteúdo proposicional da mensagem" (p. 86). Nesse sentido, o autor esclarece que, sob o viés ideacional, a linguagem se configura como um conjunto de recursos linguísticos usados para estabelecer relações e se referir a elementos do mundo.

Evidências

léxico-grama-

ticais de repre-

sentações na

voz de ativistas

e de homos-

sexuais idosos.

97

Essa função representacional ${ }^{4}$ da linguagem, no estrato da léxico-gramática, é realizada pelo sistema de transitividade, o qual permite construir o mundo das experiências por meio de tipos de processos. Halliday e Matthiessen (2004, p. 170) apontam que "cada tipo de processo apresenta seu próprio modelo ou esquema para construir um domínio particular da experiência, uma figura de um tipo particular" ${ }^{5}$. A noção de figura, para os autores, refere-se a uma categoria semântica que expressa o significado manifestado pela relação estabelecida entre processo (as propriedades temporais da experiência), participantes (os envolvidos no processo) e, eventualmente, circunstâncias (informações que contextualizam a experiência expressa pelo processo), podendo estabelecer figuras de fazer e acontecer, sentir, ser, dizer, existir e comportar-se. Cada um desses componentes da figura é tipicamente realizado por categorias gramaticais específicas: os processos são realizados por grupos verbais, os participantes por grupos nominais e as circunstâncias por grupos adverbiais e sintagmas preposicionais.

O Quadro 1 resume os tipos de processos e respectivos partici-

\footnotetext{
4. O conceito de representação da experiência proposto pela LSF se aproxima ao conceito de representação social proposto pela Psicologia Social, uma vez que essa perspectiva compreende que representar corresponde ao ato cognitivo no qual um indivíduo refere-se a um dado objeto. Para os psicólogos sociais, representações sociais correspondem às formas de compreender o mundo de modo compartilhado entre os indivíduos de uma dada comunidade (JODELET, 2001).

5. Tradução nossa de "Each process type provides its own model or schema for construing a particular domain of experience as a figure of a particular kind".
} 
pantes com exemplos extraídos do corpus deste trabalho.

\begin{tabular}{|c|c|c|c|c|}
\hline \multirow[b]{2}{*}{$\begin{array}{r}\text { Thiago Santos } \\
\text { da Silva }\end{array}$} & & & \multicolumn{2}{|l|}{ Atributo } \\
\hline & Mentais & $\begin{array}{l}\text { sentir, perce- } \\
\text { ber, pensar e } \\
\text { desejar }\end{array}$ & $\begin{array}{l}\text { Experienciador } \\
\text { Fenômeno }\end{array}$ & $\begin{array}{l}\text { Gloria Donadello } \\
\text { se lembra de seu } \\
\text { doloroso encontro } \\
\text { com a intolerân- } \\
\text { cia [...]. }\end{array}$ \\
\hline $\begin{array}{r}\text { Cristiane } \\
\text { Fuzer }\end{array}$ & \multirow[b]{2}{*}{ Relacionais } & \multirow[b]{2}{*}{$\begin{array}{l}\text { relação entre } \\
\text { duas entidades: } \\
\text { caracterização } \\
\text { ou identificação }\end{array}$} & $\begin{array}{l}\text { Portador } \\
\text { Atributo }\end{array}$ & 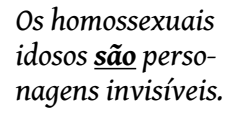 \\
\hline \multirow[t]{4}{*}{98} & & & $\begin{array}{l}\text { Identificado } \\
\text { Identificador }\end{array}$ & $\begin{array}{l}\text { Nesse contexto, o } \\
\text { ABC bailão é um } \\
\text { dos poucos terri- } \\
\text { tórios livres para } \\
\text { os homossexuais } \\
\text { acima dos } 60 \text {. }\end{array}$ \\
\hline & Verbais & dizer & $\begin{array}{l}\text { Dizente } \\
\text { Verbiagem } \\
\text { Receptor } \\
\text { Alvo } \\
\end{array}$ & $\begin{array}{l}\text { Gays idosos pe- } \\
\text { dem respeito na } \\
\text { Parada Gay }\end{array}$ \\
\hline & Existenciais & existir & Existente & $\begin{array}{l}\text { Parece que os } \\
\text { gays idosos são } \\
\text { invisíveis não } \\
\text { é verdade? Mas } \\
\text { eles existem. }\end{array}$ \\
\hline & $\begin{array}{l}\text { Comportamen- } \\
\text { tais }\end{array}$ & comportar-se & $\begin{array}{l}\text { Comportante } \\
\text { Comportamento }\end{array}$ & $\begin{array}{l}\text { Gays idosos } \\
\text { convivem com } \\
\text { a homofobia em } \\
\text { asilos }\end{array}$ \\
\hline
\end{tabular}

Quadro 1 - Resumo dos tipos de orações (adaptado de Fuzer, 2008, p. 126-127, com base em Halliday e Matthiessen, 2004).

As orações mentais e verbais apresentam a particularidade de projetar outras orações (ou combinação delas). Isso ocorre quando, no lugar do participante Fenômeno ou Verbiagem, houver uma oração exprimindo o conteúdo do sentir ou dizer expresso pelo processo. Um exemplo é Ele lembra que só em 1969 a homossexualidade deixou de ser proibida por lei na Alemanha, em que o processo mental lembra projeta a oração que só em 1969 a homossexualidade deixou de ser proibida por lei na Alemanha.

Nas orações verbais, a projetada pode se apresentar de duas 
formas: Citação, que se configura como a reprodução da fala do Dizente, e Relato, que se refere ao dizer expresso por uma oração tipicamente iniciada por "que" ou "se". Um exemplo de Citação é o trecho sublinhado em 'Eu me sentia como uma pária' disse Gloria. Já um exemplo de Relato é a passagem sublinhada em Maria Stella Pires, de 66 anos e pioneira na luta pelos direitos lésbicos, porém, diz que com os mais jovens, ela e suas colegas têm aprendido uma boa lição. Nos dois exemplos, o processo dizer projeta duas outras orações cujo conteúdo é atribuído a outras vozes (com base em MARTIN; WHITE, 2005). Esse recurso léxico-gramatical tem singular importância neste trabalho, uma vez que os textos analisados instanciam gêneros jornalísticos em que a inclusão de outras vozes é uma prática recorrente. Por isso, esse recurso linguístico foi considerado na metodologia emprega-

Evidências léxico-gramaticais de representações na voz de ativistas e de homossexuais idosos.

99 da, descrita na seção seguinte. 0 foco está na análise do sistema de transitividade, que nos possibilita identificar representações sobre homossexuais idosos em dois âmbitos: no léxico-gramatical, em que se verificam evidências de representações para o grupo social em questão, e no âmbito semântico, em que os significados representacionais são categorizados.

\section{Metodologia}

Por ser a teoria sistêmico-funcional uma abordagem em que a relação entre texto e contexto se faz necessária, nesta seção, inicialmente, estão apresentados dados a respeito do corpus, a fim de informar sobre o contexto em que os textos analisados aparecem. $\mathrm{Na}$ sequência, estão descritos os procedimentos da análise linguística do corpus.

\section{O corpus de análise}

Para a coleta de textos que abordam a homossexualidade na terceira idade, foi utilizado o website de busca Google, usando-se como as palavras de busca as expressões "homossexuais idosos" e "gays idosos". Após a aplicação de critérios que delimitaram o corpus em estudo, tais como a seleção de textos escritos em língua portuguesa, o descarte dos textos relacionados à pornografia e eliminação dos textos publicados em blogs - uma vez que o objetivo proposto para o trabalho era analisar os textos da mídia -, chegamos a um total de 19 textos, todos publicados no período de 2006 a 2010, conforme os dados apresenta- 
dos no Quadro 2.

Thiago Santos

da Silva

Cristiane

Fuzer

100

\begin{tabular}{|c|c|c|c|}
\hline Código & Título do texto & $\begin{array}{l}\text { Fonte de } \\
\text { publicação }\end{array}$ & $\begin{array}{l}\text { Data de } \\
\text { publicação }\end{array}$ \\
\hline$[\mathrm{A} 01]$ & Homossexuais idosos & CMI Brasil & $12 / 02 / 2008$ \\
\hline$[\mathrm{A} 02]$ & Os idosos gays & Portal ACapa & $24 / 09 / 2009$ \\
\hline [N01] & $\begin{array}{l}\text { Gay Idoso espancado e morto na } \\
\text { Baixada Fluminense }\end{array}$ & Revista Lado A & $06 / 10 / 2006$ \\
\hline [N02] & $\begin{array}{l}\text { Berlim terá primeiro asilo para } \\
\text { idosos gays }\end{array}$ & BBC Brasil & $15 / 01 / 2008$ \\
\hline [N03] & $\begin{array}{l}\text { Defesa dos gays idosos também é } \\
\text { discutida na Parada de SP }\end{array}$ & Portal G1 & $25 / 05 / 2008$ \\
\hline$[\mathrm{N} 04]$ & Projeto & Portal O Fuxico & $25 / 07 / 2008$ \\
\hline [N05] & $\begin{array}{l}\text { Metrô e ônibus de Nova York } \\
\text { terão fotos de gays idosos }\end{array}$ & Portal ACapa & $14 / 10 / 2008$ \\
\hline [N06] & $\begin{array}{l}\text { APlace to Live-Documentário aborda } \\
\text { gays e lésbicas na terceira idade }\end{array}$ & $\begin{array}{l}\text { Portal } \\
\text { Dykerama }\end{array}$ & $26 / 02 / 2009$ \\
\hline [N07] & $\begin{array}{l}\text { Terceira idade chega à Parada } \\
\text { Gay de São Paulo }\end{array}$ & $\begin{array}{l}\text { Portal do Jornal } \\
\text { Estadão }\end{array}$ & $13 / 06 / 2009$ \\
\hline [N08] & $\begin{array}{l}\text { Aposentado na parada pede } \\
\text { amor aos gays idosos }\end{array}$ & $\begin{array}{l}\text { Portal do Jor- } \\
\text { nal Agora }\end{array}$ & $15 / 06 / 2009$ \\
\hline [N09] & $\begin{array}{l}\text { Gays idosos têm asilo de luxo na } \\
\text { Espanha }\end{array}$ & Portal Cena G & $23 / 09 / 2009$ \\
\hline [N10] & Uma noite no Bailão & $\begin{array}{l}\text { Portal } \\
\text { Arco-Íris News }\end{array}$ & $20 / 05 / 2010$ \\
\hline [R01] & $\begin{array}{l}\text { Gays idosos convivem com a } \\
\text { homofobia em asilos }\end{array}$ & Portal ACapa & $09 / 07 / 2007$ \\
\hline [R02] & $\begin{array}{l}\text { Para gays, asilos significam "vol- } \\
\text { ta ao armário" }\end{array}$ & Portal Terra & $15 / 10 / 2007$ \\
\hline [R03] & $\begin{array}{l}\text { Gays idosos pedem respeito na } \\
\text { Parada Gay }\end{array}$ & Revista Lado A & $17 / 06 / 2009$ \\
\hline [R04] & $\begin{array}{l}\text { Espanhóis lançam asilo de luxo } \\
\text { para idosos gays }\end{array}$ & BBC Brasil & $23 / 09 / 2009$ \\
\hline [R05] & $\begin{array}{l}\text { Lar de luxo para idosos LGBT - } \\
\text { Território livre de homofobia? }\end{array}$ & $\begin{array}{l}\text { Portal Parada } \\
\text { Lésbica }\end{array}$ & $23 / 09 / 2009$ \\
\hline [R06] & $\begin{array}{l}\text { Filme sobre balada gay da } 3^{a} \text { idade } \\
\text { se destaca entre curtas do Cine PE }\end{array}$ & Portal G1 & $29 / 04 / 2010$ \\
\hline [R07] & Preconceito sem idade & $\begin{array}{l}\text { Diário de São } \\
\text { Paulo Online }\end{array}$ & $04 / 06 / 2010$ \\
\hline
\end{tabular}

Quadro 2 - Dados sobre o corpus da pesquisa (SILVA, 2012, p. 76-77).

Os textos selecionados segundo os critérios incluem artigos de opinião, notícias e reportagens. A seleção de textos de diferentes propósitos sociocomunicativos e fontes de publicação se deve a pouca quantidade de material encontrado no período de constituição do corpus (2010 a 2012). Essa escassez de material, a nosso ver, é sintomática, indicando que os gays na terceira idade parecem ainda não 
ser pauta jornalística.

Para facilitar a organização da análise, os textos foram arranjados por meio dos códigos "A" (para artigo de opinião). "N" (para notícia) e "R" (para reportagem), seguida por um número sequencial.

Evidências

léxico-grama-

ticais de repre-

sentações na

voz de ativistas

e de homos-

sexuais idosos.

101 foi possível constatar a grande quantidade de verbos de dizer no corpus, o que nos levou a considerar a presença de outros discursos, além daquele manifestado na voz do produtor do texto. Com base nesse resultado preliminar, o segundo passo foi destacar dos textos as vozes não autorais, isto é, todo dizer que não pudesse ser atribuído ao autor do texto (MARTIN; WHITE, 2005). O terceiro passo foi a separação dessas vozes por papéis sociais, que resultou em: ativistas, profissionais de asilo, profissionais de cinema e os próprios homossexuais idosos. O quarto passo consistiu na seleção das Citações e Relatos em que os dizeres são atribuídos às vozes dos ativistas e dos homossexuais idosos ${ }^{6}$. Considerando as Citações e Relatos destacados, o último passo consistiu na análise das orações que fizessem referência, linguisticamente, aos homossexuais na terceira idade.

A segunda etapa teve por finalidade a análise das funções léxico-gramaticais do sistema de transitividade das orações que manifestam representações na voz dos ativistas e na dos homossexuais idosos. A partir dos dados obtidos, verificamos, com base em evidências léxico-gramaticais, como os homossexuais na terceira idade são representados nos textos que compõem o corpus.

\section{Análises dos resultados}

Nesta seção, apresentamos a análise do sistema de transitividade das orações em enunciados atribuídos às vozes selecionadas para o presen-

6. Em Silva (2012), estão apresentadas as análises linguísticas das representações manifestadas nas orações atribuídas às demais vozes. 
Thiago Santos

da Silva

Cristiane

Fuzer

102

te estudo. Na seção a seguir, apresentamos a descrição léxico-gramatical e interpretação de excertos em que o dizer é atribuído aos ativistas, bem como a identificação das representações encontradas na voz do grupo. De modo similar, na próxima seção, analisamos as representações presentes na voz dos próprios homossexuais idosos. Para encerrar a análise dos resultados, na seção subsequente, apresentamos uma discussão sobre as representações encontradas nos dois conjuntos de vozes analisados, bem como estabelecemos paralelo entre elas identificando semelhanças e diferenças.

\section{Representações na voz de ativistas}

A voz de ativistas corresponde a falas atribuídas a pessoas que militam tanto em defesa dos direitos dos homossexuais idosos, quanto dos LGBTs $^{7}$ em geral. Ocorrências dessas vozes foram encontradas em 10 dos 19 textos que compõem o corpus. Quando chamados a se manifestar, os ativistas justificam e/ou discutem a necessidade de criação (ou não) de asilos exclusivos para homossexuais, apresentando características específicas para os homossexuais mais velhos.

Com base na análise léxico-gramatical das orações que compõem o discurso dos ativistas, identificamos a existência de três representações para os homossexuais idosos: a) vítimas de duplo preconceito; b) solitários e c) desamparados politicamente.

No segmento que segue, há um exemplo ${ }^{8}$ em que os homossexuais idosos são representados como vítimas de preconceito. Nele, o ativista Toni Reis, presidente da Associação Brasileira LGBT, uma das mais importantes instituições de defesa dos direitos dos homossexuais no Brasil, discute a situação vivida em asilos tradicionais ${ }^{9}$.

\footnotetext{
7. Sigla que se refere a Lésbicas, Gays, Bissexuais, Transexuais/Travestis.

8. Nos excertos utilizados como exemplos, todas as orações estão numeradas, porém, somente as que estão em itálico são analisadas. A numeração das orações é feita considerando os componentes fundamentais. Em negrito estão destacados os termos referentes a homossexuais idosos que, quando em elipse, são explicitados entre colchetes simples.

9. Neste trabalho, entendemos por asilo tradicional ou casa de repouso tradicional asilos não exclusivos para homossexuais, isto é, lugares onde a orientação sexual não é condição para que o idoso seja morador.
} 
(1) O medo da rejeição em asilos, por exemplo, é um fantasma. (2) "Eles [homossexuais idosos] preferem esconder sua condição (3) [homossexuais idosos] temendo o preconceito, seja por parte dos colegas ou até dos próprios cuidadores", (4) diz Toni Reis, presidente da Associação Brasileira LGBT, que recebe cada vez mais denúncias de discriminação. [R07]

Nas orações (2) e (3) desse segmento, os homossexuais idosos, recuperados textualmente pelo pronome eles, desempenham a função léxico-gramatical de Experienciador dos processos preferir e temer. Os Fenômenos percebidos são esconder sua condição e o preconceito, seja por parte dos colegas ou até dos próprios cuidadores. Essas estruturas indicam que, na voz do militante, os homossexuais são representados em função de suas escolhas e temores. Por isso, para não sofrerem discriminação em asilos tradicionais, eles optam por se manterem reservados quanto a sua homossexualidade. Esses dados linguísticos mostram que, em asilos

\section{Evidências} léxico-gramaticais de representações na voz de ativistas e de homossexuais idosos. tradicionais, os homossexuais estão constantemente sujeitos a atitudes homofóbicas.

Além de serem vítimas de preconceito por conta da orientação sexual que possuem, eles também sofrem preconceito por serem pessoas idosas. Essa situação é evidenciada no excerto a seguir atribuído ao publicitário aposentado e escritor Ricardo Rocha Aguieiras ${ }^{10}$, militante que defende a visibilidade dos homossexuais mais velhos.

(1) Ricardo declarou à jornalista Juliana Cardilli: (2) "Eles [homossexuais idosos] sofrem duplo preconceito, (3) por [homossexuais idosos] serem idosos (4) e por [homossexuais idosos] serem gays". [A02]

A Citação atribuída a Ricardo Aguieiras inicia com uma oração mental (2), em que os homossexuais idosos, recuperados pelo pronome eles, desempenham a função de Experienciador do processo sofrer, cujo Fenômeno é duplo preconceito. A escolha por essa configuração léxico-gramatical mostra que os homossexuais experienciam preconceitos que são comuns a duas parcelas da população bem marcadas socialmente. $\mathrm{O}$ esclarecimento de quais são as causas desses preconceitos está nas

10.Ricardo Aguieiras é um participante recorrente nos textos analisados, por conta de sua luta em defesa da visibilidade dos homossexuais mais velhos. Ele aparece tanto no conjunto de vozes composto por ativistas quanto no composto por vozes dos próprios homossexuais idosos. Assim, em alguns textos, Aguieiras aparece como um ativista que luta por uma causa que não é apenas sua, enquanto em outros é apresentado como um homossexual idoso, militando em causa própria. 
Thiago Santos da Silva

Cristiane

Fuzer

orações (3) e (4) do excerto. Nessas orações, os referidos homossexuais, desempenhando a função de Portador dos Atributos idosos e gays, são caracterizados como possuidores de duas condições humanas desvalorizadas socialmente, o envelhecimento e a orientação sexual desviante.

Um exemplo em que homossexuais mais velhos são representados como solitários aparece no segmento a seguir, atribuído ao ativista Antonio Gutiérrez, um dos idealizadores de um projeto de criação de asilo para homossexuais na Espanha. Em seu discurso, o militante caracteriza essa parcela da comunidade homossexual.

(1) "Consideramos que (2) a maioria dos idosos homossexuais tem pouquíssimo apoio familiar (3) e normalmente [idosos homossexuais] não tiveram filhos; (4) portanto sua solidão é maior. (5) Fazer espaços como este representa uma ajuda (6) para que os gays se sintam à vontade (7) e [os gays] não tenham um forçado regresso ao armário", (8) completou. [R04]

Nas orações (2), (3) e (4), idosos homossexuais são caracterizados por Atributos que frequentemente não possuem (filhos), possuem pouco (pouquíssimo apoio familiar) e, por conseguinte, pelo grau de solidão que possuem (maior do que a vivida pelos heterossexuais). Em consequência dessa representação como solitários, já que não têm mais os pais vivos nem tiveram filhos para lhes fazer companhia durante a velhice, os homossexuais idosos desempenham as funções Experienciador em (6) (se sintam à vontade) e de Portador do Atributo em (7) (um forçado regresso ao armário). Nesse caso, por conta do desamparo familiar, muitos homossexuais idosos acabam indo morar em asilos tradicionais, onde, para não sofrerem ataques homofóbicos, sentem-se obrigados a "voltar para o armário"11.

As escolhas linguísticas atribuídas ao ativista Antonio Gutiérrez, nos textos em análise, representam os homossexuais idosos mais solitários do que os heterossexuais idosos. Seu argumento baseia-se na observação de que a maioria dessas pessoas perdeu o contato com a família. Essa solidão acaba fazendo com que eles, caso busquem um asilo tradicional para viver, escondam a orientação sexual.

11. A expressão "voltar para o armário" faz oposição a "sair do armário", cujo significado é assumir publicamente a sexualidade. Assim, a expressão "voltar para o armário" significa retornar a esconder a orientação sexual que um dia foi assumida. 
Em outro dizer atribuído a Gutiérrez, há uma articulação entre as representações solitários e desamparados, conforme excerto que segue.

(1) Um dos criadores do projeto, o ativista Antonio Guitiérrez disse (2) que $a$ idéia é acabar com um problema social: a solidão e o desamparo dos gays na terceira idade. (3) "Na Espanha, não existem abrigos destinados a idosos LGBT. (4) São iniciativas necessárias (5) porque existe um problema social" (6) explica Gutiérrez. [N09]

$\mathrm{Na}$ oração (2), homossexuais idosos são referidos por um sintagma preposicional (dos gays na terceira idade) que, por sua vez, integra o grupo nominal que desempenha o papel do Identificador (acabar com um problema social: a solidão e o desamparo dos gays na terceira idade). Em (3), idosos LGBT compõem o grupo nominal que tem função de Existente (abrigos destinados a idosos LGBT). Tanto no Identificador quanto no Existente há metáforas gramaticais realizadas, respectivamente, pela nominalização desamparo ("desamparar") e pela adjetivação destinados ("destinar") ${ }^{12}$. As formas congruentes das orações seriam "Os gays na terceira idade estão desamparados" e "Abrigos são destinados a idosos LGBT". Nessas construções, os homossexuais idosos desempenham, respectivamente, a função de Meta do processo desamparar e de Beneficiário do processo destinar, evidenciando sua condição passiva diante da situação vivenciada nos asilos.

Essas escolhas linguísticas representam os homossexuais idosos como solitários e desamparados de ações que os protejam e os auxiliem a viver a sua orientação sexual sem serem discriminados. Isso é explicado, no dizer atribuído a Gutiérrez, pelo tratamento diferenciado que essa população deveria receber, mas que, por não existirem políticas protetivas específicas para essa parcela LGBT, acaba não recebendo.

Essa representação, de forma mais explícita, aparece na fala de

\footnotetext{
12. Nominalização e adjetivação são termos usados por van Leeuwen (1997) para se referir, respectivamente, ao emprego de um grupo nominal no lugar de um grupo verbal (desamparo $\rightarrow$ desamparar) e de um adjetivo no lugar de um grupo verbal (destinado $\rightarrow$ destinar). Essas configurações linguísticas são tipos de metáfora gramatical (HALLIDAY e MATTHIESSEN, 2004), ou seja, o emprego de uma categoria gramatical, que tipicamente realiza uma determinada função, para exprimir outra função não típica - no caso em análise, a metáfora gramatical permite que processos desempenhem a função de participantes da oração.
}

Evidências

léxico-grama-

ticais de repre-

sentações na

voz de ativistas

e de homos-

sexuais idosos.

105 
Aguieiras, na seguinte passagem:

(1) "Não há nenhuma política de proteção do gay idoso. (2) E o idoso no Brasil já é tratado como lixo", explica Aguieiras. [N03]

Thiago Santos da Silva

Cristiane

Fuzer

106

Na oração (1), o sintagma preposicional do gay idoso integra o grupo nominal que desempenha o papel de Existente: nenhuma política de proteção do gay idoso. Aprofundando um pouco mais a análise, podemos notar que no Existente há uma metáfora gramatical realizada pela nominalização de um processo material (proteção). A forma congruente para a estrutura é "nenhuma política protege o gay idoso", em que esses indivíduos passam a ser Beneficiário do processo proteger. A polaridade negativa associada ao Existente contribui para representar os homossexuais idosos, nesse segmento, como cidadãos não beneficiados por políticas protetoras, ou seja, como pessoas desamparadas em termos de direito.

As análises demonstram que, na voz dos ativistas, as escolhas linguísticas representam os homossexuais idosos como vítimas de duplo preconceito: como pessoas solitárias e desamparadas politicamente em termos de direitos de proteção.

\section{Representações na voz de homossexuais idosos}

Ocorrências da voz de homossexuais idosos foram encontradas em 7 dos 19 textos do corpus. A atribuição do dizer a essa voz serve, em alguns casos, para exemplificar como os homossexuais na terceira idade são tratados pela família e como vivem em asilos tradicionais; em outros, para trazer informações de como esse grupo social vivencia a sexualidade e apresentar opiniões a respeito da sua situação.

A análise léxico-gramatical das orações atribuídas a essa voz evidenciou que os homossexuais idosos compartilham com os ativistas duas representações sobre o grupo social em estudo: vítimas de duplo preconceito e solitários. A terceira representação manifestada no discurso atribuído à voz dos homossexuais idosos, entretanto, é diferente: partícipe em espaços considerados homossexuais.

A primeira representação pode ser exemplificada pela fala de Gloria Donadello, uma senhora de 81 anos que conta uma experiência traumática vivida em um asilo tradicional, no Novo México, Estados Unidos. Nos segmentos a seguir, Donadello conta sobre o preconceito sofrido no asilo. 
(1) Mesmo agora, aos 81 anos e enfrentando problemas de memória, Gloria Donadello se lembra de seu doloroso encontro com a intolerância em uma casa de repouso em Santa Fé, Novo México. (2) Sentada na companhia de pessoas que via como amigos, (3) "elas estavam rindo (4) e fazendo comentários de um certo tipo, (5) e eu lhes disse: (6) 'Não façam assim, por favor, (7) porque eu sou homossexual"'. (8) As consequências de sua franqueza, disse Donadello, foram rápidas e impiedosas. (9) "Todo mundo parecia horrorizado", conta. [R02]

(1) Com a deterioração de sua saúde emocional, Donadello se transferiu a uma comunidade adulta nas redondezas (2) que atende a homens e mulheres homossexuais. (3) "[eu] Senti-me um pária", (4) ela disse, já acomodada à sua nova moradia. (5) "Para mim, era uma escolha entre a vida e a morte". [R02]

No primeiro fragmento, na oração (5), a lésbica idosa, referida pelo pronome $e u$, desempenha a função de Dizente, explicitando sua

\section{Evidências}

léxico-grama-

ticais de repre-

sentações na

voz de ativistas

e de homos-

sexuais idosos.

107 participação no discurso como alguém que compartilha suas experiências pessoais. Em (7), Donadello se inclui na classe homossexual, Atributo do qual é Portador. Essas escolhas léxico-gramaticais representam a idosa no momento em que manifesta publicamente sua orientação sexual. A consequência de sua "saída do armário" está representada no segundo fragmento. Ao desempenhar a função de Experienciador em senti-me uma pária, a mulher representa sua tristeza quando seus colegas de asilo começaram a excluí-la das atividades realizadas.

Esses dados linguísticos mostram que, nesse caso, a lésbica idosa, como integrante do grupo social em estudo, é representada como discriminada, em asilos tradicionais, por ser homossexual. Assim como verificamos no discurso dos ativistas, a representação como vítimas de preconceito devido à orientação sexual que manifestam também aparece no discurso de quem vivencia essa experiência. 0 preconceito também é sentido pelos homossexuais na terceira idade em decorrência da idade avançada que possuem. No dizer atribuído a Ricardo Rocha Aguieiras, representante da categoria dos gays idosos, expressa-se a situação vivenciada pelo grupo quanto a relacionamentos amorosos, como evidencia a análise do segmento a seguir. 
(1) $O$ aposentado Ricardo Aguieiras, 61 anos, segurava uma placa: "Gays idosos também são (muito) gostosos". (2) E solicitava: (3) "Seja corajosa, (4) ame uma lésbica idosa!" (5) "Muitas vezes, mesmo estando apaixonado, (6) o jovem não namora o idoso (7) porque tem vergonha de apresentar [o idoso] aos amigos. (8) Isso pode levar esse gay mais velho a voltar para o armário e acabar em um asilo", (9) acredita Aguieiras, de bermuda justa e curta, cabelos tingidos e bota de cano alto. (10) Sem namorado, ele diz (11) que [ele] não tem problema em aceitar a idade. [N08]
Thiago Santos

da Silva

Cristiane

Fuzer

108

Na oração (4), uma lésbica idosa desempenha a função de Fenômeno com relação ao processo ame. Já em (6), o idoso realiza função de Meta com relação ao processo namora. 0 Ator que (não) namora o idoso é o jovem. Nas duas orações, o homossexual idoso parece não despertar o interesse ou a coragem do jovem em estabelecer um relacionamento amoroso. A causa dessa situação está representada na oração encaixada (de apresentar aos amigos) presente em (7), em que o idoso aparece como Escopo com relação ao processo apresentar. Assim, o fato de o jovem ter vergonha de mostrar aos amigos também jovens que está se relacionando afetivamente com um idoso possibilita a interpretação de que os homossexuais idosos sofrem preconceito dentro da própria comunidade LGBT.

Essa situação envolvendo os jovens gera consequências na vida dos homossexuais mais velhos, representadas na oração (8). Nessa oração, voltar para o armário é uma metáfora que alude ao comportamento inverso ao das pessoas que resolvem manifestar publicamente sua condição homossexual. Esses dados reforçam a representação de que os homossexuais idosos são solitários, também manifestada no discurso dos ativistas analisado na seção anterior. A causa da solidão, porém, é diferente: a dificuldade de relacionamento amoroso, principalmente quando o parceiro com que deseja se relacionar é mais jovem.

Uma representação encontrada apenas no discurso dos homossexuais idosos é a de partícipe em espaços considerados homossexuais, como a Parada Gay de São Paulo e boates/bares gays . Um exemplo dessa representação pode ser observado no próximo excerto, em que o homossexual idoso Ricardo Aguieiras se manifesta a respeito da presença do grupo na Parada Gay.

(1) “Nós ainda não somos muitos, (2) porém [nós] estamos em maior número do que nas ediçôes anteriores", (3) afirma Ricardo Aguieiras, de 61 anos, (4) que há seis é militante das causa dos idosos gays. [N07] 
No dizer atribuído a Aguieiras, há o emprego de um "nós exclusivo" (FAIRCLOUGH, 2003), que indica a inclusão do autor no grupo dos participantes da Parada Gay, sem que o leitor seja necessariamente incluído nesse grupo. Dessa forma, demonstra uma identidade para o grupo social do qual somente os leitores homossexuais idosos podem se incluir, ficando os demais leitores excluídos dessa participação.

Tanto em (1) quanto em (2), na função de Portador, os homossexuais idosos são caracterizados como um grupo que, embora tenha pouca participação na Parada Gay de São Paulo (haja vista a polaridade negativa em não somos muitos), aos poucos está buscando ganhar visibilidade em espaços frequentados por homossexuais mais jovens.

Essas escolhas léxico-gramaticais indicam que, na voz de Aguieiras, os homossexuais são vistos como pessoas que, mesmo de forma in-

Evidências léxico-gramaticais de representações na voz de ativistas e de homossexuais idosos. cipiente, buscam maior visibilidade em espaços de manifestação dos homossexuais e, consequentemente, buscam legitimar seu espaço dentro do movimento LGBT. Resumindo, na voz dos próprios homossexuais, o grupo continua sendo representado como vítima de duplo preconceito e solitário, mas cada vez mais presente em espaços de socialização entre homossexuais.

\section{Análise das representações e de suas relações}

As representações vítimas de duplo preconceito e solitários - evidenciadas pelas escolhas léxico-gramaticais analisadas -, na voz dos ativistas e na dos próprios homossexuais mais velhos permitem a constatação de que os homossexuais idosos, como salienta Correia (2009), encontram-se na intersecção de duas condições do ser humano ainda bastante discriminadas na sociedade brasileira: velhice e homossexualidade.

Com relação ao preconceito quanto à sexualidade, podemos destacar o fato de que, historicamente, os homossexuais foram considerados invertidos, anormais. Essa representação está baseada em uma concepção recente, pois até 1990 a homossexualidade era considerada pela Organização Mundial de Saúde como uma doença, uma anormalidade passível de tratamento e de cura (ASSOCIAÇÃo BRASILEIRA DE LÉSBICAS, GAYS, BISSEXUAIS, TRAVESTIS E TRANSEXUAIS, 2009). Assim, essa visão a respeito da orientação homossexual como um distúrbio ainda pode ser percebida no preconceito sofrido pelos homossexuais em asilos tradicionais, manifestado nos textos analisados, tal como a fala atribuída a Toni Reis, que menciona o fato de alguns homossexuais idosos 
Thiago Santos da Silva

Cristiane

Fuzer

precisarem omitir sua orientação sexual, a fim de evitar manifestações de preconceito por parte de colegas e cuidadores em asilos tradicionais.

Quanto ao preconceito com relação à velhice, a representação está baseada numa visão de idoso como inválido, inútil. Essa concepção está associada à ideia preconcebida de que, em uma sociedade capitalista, as pessoas são valoradas segundo sua capacidade produtiva e, por conseguinte, de consumo. Com isso, torna-se naturalizado o desprezo pelos mais velhos, uma vez que a sua capacidade de produção e consumo diminui à medida que a idade aumenta (MACHADO, 2008).

No que se refere à representação dos homossexuais idosos como solitários, as causas de tal solidão são representadas diferentemente na voz dos ativistas e na dos próprios homossexuais. Para os ativistas, a causa da solidão é o reduzido apoio que essa parcela da comunidade gay recebe dos familiares, especialmente pais e irmãos. Esse abandono ocorre porque, nos casos em que o então idoso assumiu publicamente sua sexualidade durante a juventude, a "saída do armário" aconteceu num período em que ser homossexual era mal visto pela sociedade, fazendo com que muitos deles fossem expulsos de casa e, consequentemente, perdessem o contato com os familiares. Ainda de acordo com os ativistas, há um agravante na solidão experienciada pelos homossexuais idosos: a inexistência de filhos. Esse argumento, por um processo de ancoragem ${ }^{13}$ conforme postulado por Moscovici (2010), suscita a ideia preconcebida de que os filhos são companhia para a velhice dos pais. Essa ideia está presente na sociedade há muito tempo, aparecendo inclusive na Bíblia, no livro do Eclesiástico (200 a. C.), no qual está descrito que a função do filho é cuidar daquele que um dia o cuidou. Consequentemente, existe uma representação compartilhada socialmente de que quem não constitui uma prole acaba por ser desassistido na velhice. Essa representação pode ser sintetizada no dizer atribuído a Antonio Gutiérrez, ativista espanhol, que refere a solidão vivenciada pelos idosos homossexuais, que, na maioria das vezes, não dispõem da companhia de familiares.

Para os próprios homossexuais idosos, por sua vez, a causa da solidão é a vergonha que muitos jovens têm de se relacionar emocional-

\footnotetext{
13. De acordo com Moscovici (2010), ancoragem consiste em colocar ideias e objetos estranhos em um contexto mais familiar, reconhecível, isto é, ao ancorar, damos nomes e classificamos alguma coisa, escolhendo para ela um dos modelos estocados em nossa memória, atribuindo um caráter positivo ou negativo à relação estabelecida.
} 
mente com um(a) parceiro(a) mais velho(a). Essa visão está ancorada não só na desvalorização do idoso, como mencionada anteriormente, mas também na ideia de que o corpo "velho" é desprovido de qualquer atributo de ordem estética e erótica, por conta de seu aspecto a-social e não desejável, como destaca Paiva (2009), como salienta Ricardo Rocha Aguieiras em sua fala sobre a vergonha que alguns jovens têm de se relacionar com um homossexual mais velho.

$\mathrm{Na}$ voz dos ativistas, surge a representação de que os homossexuais idosos são pessoas desamparadas por políticas de proteção. Se forem consideradas as leis (ou projeto de leis) que visam proteger cada uma das duas condições humanas que constituem os membros desse grupo (a de idoso e a de homossexual), observamos que os projetos de leis existentes são recentes. Se, isoladamente, no caso do idoso, a discussão sobre me-

\section{Evidências}

léxico-gramaticais de representações na voz de ativistas e de homossexuais idosos. didas de proteção é recente (Estatuto do Idoso, Lei № 10.741/2003) e, no caso do homossexual, ainda se encontra incipiente e inconcluso - como o projeto de Lei 122/06 destinado à punição da discriminação por orientação sexual, que há quase uma década está em tramitação no Senado Federal -, no que se refere à pessoa que congrega as duas condições a discussão de leis protetivas ainda nem começou a ser pensada.

As representações aqui analisadas veiculam caracterizações negativas a respeito dos homossexuais idosos, indicando a situação de vulnerabilidade em que o grupo vive, seja em termos de tratamentos em asilos tradicionais e de relacionamentos afetivos, seja com relação a medidas de proteção como um direito. No entanto, há uma representação que, de certa forma, caracteriza positivamente esse grupo social: a de que os homossexuais idosos fazem-se presentes em espaços de socialização. Isso demonstra certa tentativa de modificação da situação em que o grupo se encontra ao buscar chamar a atenção da sociedade para a problemática da homossexualidade na terceira idade. Assim, são representados como um grupo, embora pequeno, de pessoas que estão buscando defender uma causa própria, como explicitado na fala atribuída ao homossexual idoso e ativista Ricardo Agueiros, segundo o qual os homossexuais mais velhos, apesar de em uma pequena quantidade, têm se feito presentes na Parada Livre de São Paulo.

Esse conjunto de representações ora negativas, ora positivas sinaliza uma situação não exclusiva aos homossexuais na terceira idade, mas aos idosos em geral: a mudança de paradigma do que é ser velho. De acordo com Debert (2007), o envelhecimento, assim como as demais ins- 
Thiago Santos

da Silva

Cristiane

Fuzer

tâncias da vida humana, é uma categoria socialmente construída, razão pela qual as formas de tratar as pessoas com mais idade varia de acordo com o contexto histórico, social e cultural. Como aponta Debert (1997), historicamente a velhice era associada à invalidez, principalmente a partir da metade do XIX com a criação dos primeiros sistemas de aposentadorias. Nesse período da vida, o trabalhador é considerado incapaz de produzir, ou seja, é inapto ao trabalho.

A noção de envelhecimento começa a se transformar, segundo Silva (2008), com o surgimento, a partir dos anos 1980, da categoria "terceira idade", que se estabelece principalmente com o aumento da longevidade e da qualidade de vida possibilitado pelos recursos medicinais e tecnológicos. Essas condições proporcionam aos indivíduos com mais idade uma nova identidade, mais positiva do que a anterior. Como membros da "terceira idade", os idosos passam a ser considerados como sujeitos ativos e partícipes na sociedade, por meio, principalmente, de suas capacidades de consumo.

Nesse processo de construção de envelhecimento positivo, destaca Silva (2008), foi necessário um novo discurso que desassociasse a velhice de signos estigmatizantes como doença, desabilidade, inatividade e declínio. Nesse sentido, instaura-se, como pontua Bezerra (2006), uma promissora indústria de serviços e produtos que considera um novo estilo de vida adotado pelos senhores e senhoras acima dos 60 anos, um estilo mais ativo, produtivo e principalmente consumidor.

Esse embate de posicionamentos ocorre de modo análogo na fala dos próprios homossexuais idosos. Como podemos observar na fala de seus representantes, o grupo em questão ora é representado positivamente, como partícipe, ora negativamente, como solitário e vítima de duplo preconceito. Essa aparente contradição no discurso dos homossexuais idosos reforça o posicionamento de Silva (2008) a respeito da (re) construção identitária dos sujeitos idosos:

ainda que não seja possível afirmar com exatidão o destino da velhice na contemporaneidade, aposto na coexistência entre as referidas identidades etárias [a velhice e a terceira idade] no imaginário cultural, de modo a ampliar tanto as descrições quanto as possibilidades de experiência satisfatória dos sujeitos (SILVA, 2008, 167). 
Nesse sentido, o discurso do grupo em estudo neste trabalho demonstra não só a mudança de paradigma do que é velho, mas também a existência simultânea de um modelo que considera o idoso como um senhor aposentado, que gosta de andar de pijama e ler jornal, e de outro modelo que compreende o sujeito na terceira idade como alguém ativo e altamente engajado em práticas de consumo e políticas.

Essa disputa de paradigmas possui grande influência do domínio midiático, visto que, dado o espaço ocupado pelos meios de comunicação na vida da sociedade, a possibilidade de trocas simbólicas entre as pessoas proporcionou a criação e alteração das formas de construir a vida social na contemporaneidade. Thompson (1998) entende que, com o advento do espaço midiático, criam-se "novas formas de ação e interação e novos tipos de relacionamentos sociais" (p. 77). Desse modo, os discursos veiculados pela mídia tendem a reforçar e, ao mesmo tempo, construir representações para o grupo social dos homossexuais idosos, situando-os nesse interstício de paradigmas.

\section{Considerações finais}

Neste trabalho, evidenciamos, por meio da análise do estrato léxico-gramatical da linguagem, representações sobre homossexuais idosos atribuídas à voz de ativistas e dos próprios homossexuais idosos, em textos jornalísticos da mídia eletrônica brasileira. Para a isso, utilizamos subsídios na Gramática Sistêmico-Funcional, proposta por Halliday e Matthiessen (2004), mais especificamente categorias do sistema de transitividade, que realiza a metafunção ideacional experiencial da linguagem.

A interpretação dos dados nos permite concluir que, tanto na voz dos ativistas quanto na dos próprios homossexuais idosos, o grupo social em questão é representado como vítima de duplo preconceito e solitário. Foram encontradas ainda representações de desamparados politicamente, na voz dos ativistas, e de presentes em espaços de socialização, na voz dos próprios homossexuais idosos.

As análises possibilitam-nos concluir que os homossexuais idosos estão num entre-lugar, por vezes ancorando-se numa representação antiga, advinda de um período em que os idosos eram vistos como velhinhos solitários e desamparados; outras vezes, recorrendo a uma nova representação para homens e mulheres na terceira idade: pessoas dinâmicas que buscam lutar por seus direitos. 
Thiago Santos da Silva

Cristiane

Fuzer

114

É justamente essa mudança de paradigma que possibilita a valoração negativa da primeira representação e a caracterização positiva da segunda, pois a primeira carrega a ideia de inatividade, finitude, enquanto a segunda acarreta exatamente o contrário, manifesta a busca por espaço na sociedade por meio da participação no movimento gay.

Portanto, nas vozes analisadas, os homossexuais na terceira idade são representados ora como suscetíveis a preconceitos por conta da idade e por conta da orientação sexual que manifestam, ora como pessoas que buscam, mesmo que seja apenas no seio da comunidade LBGT, visibilidade.

\section{Referências}

ASSOCIAÇÃo Brasileira de Lésbicas, Gays, Bissexuais, Travestis e Transexuais. Manual de comunicação LGBT. Paraná: ABGLT, 2009.

BARBARA, L., MACÊDO, C. M. M. Linguística Sistêmico-Funcional para a análise de discurso: um panorama introdutório. Cadernos de Linguagem e Sociedade, Brasília, v. 10, n. 1, nov., 2010, p. 89104. Disponível em: <http://seer.bce.unb.br/index.php/les/article/view/ 1212/871>. Acesso em: 13 dez. 2010.

BEZERRA, A. K. G. "A construção e reconstrução da imagem do idoso pela mídia televisiva." Biblioteca on-line de Ciências da Comunicação. Campina Grande, jan, 2006. Disponível em: <http:// bocc.unisinos.br/pag/guedes-ada-imagem-idoso-midia-televisiva.pdf>. Acesso em: 30 mar 2015.

BRASIL. Estatuto do idoso. Brasília (DF): Senado Federal, 2003.

CORREIA, C. A. C. Homossexualidade e velhice: a dupla estigmatização. 2009. 161f. Dissertação (Mestrado em Gerontologia) - Pontifícia Universidade Católica de São Paulo, São Paulo, 2009.

DAMASCENO, G. L. N.; RODRIGUES, V. V.; NOBRE, M. M. R. A metáfora da transitividade no gênero notícia jornalística: uma abordagem sistêmico-funcional. Signótica, v. 26, n. 2, p. 495-517, jul./dez. 2014. 
DEBERT, G. G. Envelhecimento e Curso da Vida. Estudos Feministas, v. 5, n. 1, jan. 1997, p. 120-128. Disponível em: <https://periodicos. ufsc.br/index.php/ref/article/view/ 12564>. Acesso em: 30 mar. 2015.

A antropologia e o estudo dos grupos e das categorias de vida.

Evidências

In: BARROS, M. M. L. (Org.). Velhice ou terceira idade?: Estudos antropológicos sobre identidade, memória e política. 4. ed. Rio de Janeiro: FGV, 2007, p. 35-48.

FAIRCLOUGH, N. Analysing Discourse: textual analysis for social research. London: Routledge, 2003.

FARENCENA, G. S.; FUZER, C. Recursos de transitividade e léxico-gramaticais de representações na voz de ativistas e de homossexuais idosos. avaliatividade na construção de representações nas fábulas "O velho e a morte", de Esopo, e "O miserável e a morte", de Millôr Fernandes. Revista do Programa de Pós-Graduação em Letras da Universidade de Passo Fundo, v. 7, n. 2, p. 233-252, jul./dez. 2011.

FUZER, C. Linguagem e representação nos autos de um processo penal: como operadores do Direito representam atores sociais em um sistema de gêneros. 2008. 270f. Tese (Doutorado em Letras) - Universidade Federal de Santa Maria, Santa Maria, 2008.

. Gramática Sistêmico-funcional da Língua Portuguesa para análise de representações sociais. Projeto de pesquisa GAP/CAL 025406. Santa Maria: DLV/CAL/ UFSM, 2009.

Contexto e léxico-gramática em interação: análise de uma sentença condenatória. Letras, Santa Maria, v. 20, n. 40, p. 113-132, jan./jun. 2010. Disponível em < file:///C:/Users/ CPUCris/Downloads/12147-52399-1-SM\%20(1).pdf> Acesso em 30 dez. 2014.

Vítimas e vilões em reality shows no Brasil: representações e avaliações com base em evidências léxico-gramaticais. ALFA, São Paulo, v. 56, n. 2, p. 403-425, 2012. Disponível em: <http://www.scielo. 
br/pdf/alfa/v56n2/03.pdf> Acesso em: 30 dez. 2014.

; FACCIN, A. Representações para a seleção brasileira de futebol a partir de evidências léxico-gramaticais. RevLet - Revista Virtual de Letras, v. 04, n. 01, jan./jul. 2012. Disponível em: < http://www. revlet.com.br/artigos/125.pdf> Acesso em: $30 \mathrm{dez} .2014$.

Thiago Santos da Silva

Cristiane

Fuzer

116
; CABRAL, S. R. S. Introdução à Gramática Sistêmico-Funcional

em Língua Portuguesa. Campinas, SP: Mercado de Letras, 2014.

HALLIDAY, M. A. K. An introduction to functional grammar. London: Arnold, 1985.

. Part I. In: HALLIDAY, M. A. K.; HASAN, R. Language, context, and text: aspects of language in social-semiotic perspective. Oxford: Oxford University, 1989.

An introduction to functional grammar. 2nd. ed. London: Routledge,1994.

HALLIDAY, M. A. K; MATTHIESSEN, C. M. I. C. An introduction to functional grammar. 3th. ed. London: Arnold, 2004.

JODELET, D. Representações sociais: um domínio em expansão. In: As representações sociais. Tradução de Lilian Ulup. Rio de Janeiro: EdUERJ, 2001, p. 17-44.

MACHADO, S. M. O discurso sobre a pessoa idosa: vozes que falam e vozes que calam. 2008. 248f. Dissertação (Mestrado em Linguística) - Universidade de Brasília, Brasília, 2008.

MARTIN, J. R.; WHITE, P. R. R. The Language of Evaluation: appraisal in English. London: Palgrave/Macmillan, 2005.

MEURER, J.L. Ampliando a noção de contexto da Linguística Sistêmico-Funcional e na Análise Crítica do Discurso. Linguagem em (Dis)curso - LemD, Tubarão, v. 4, n.esp., p. 133-157, 2004. 
MOSCOVICI, S. Representações sociais: investigações em psicologia social. Tradução de Pedrinho Guareschi. 7ed. Petrópolis: Vozes, 2010.

MOTA, M. P. Homossexualidade e Envelhecimento: algumas reEvidências flexões no campo da experiência. SINAIS - Revista Eletrônica léxico-grama- Ciências Sociais. Vitória: CCHN, UFES, Edição n.06, v.1, Dez. 2009. p. 26-51. Disponível em <http://www.pucgoias.edu.br/ucg/ unati/ArquivosUpload/1/file/Artigos\%20e\%20Cap\%C3\%ADtulos\%20de\%20 Livros/Homossexualidade\%20e\%20Envelhecimento\%20\%20algumas\%20 reflex\%C3\%B5es\%20no\%20campo\%20da\%20experi\% C3\%AAncia.pdf>. Acesso em 22 fev. 2011. ticais de representações na voz de ativistas e de homossexuais idosos.

O BAILÃo. Direção: Marcelo Caetano Produção: Flora Lahuerta, Jurandir Muller, Marcelo Caetano. Roteiro: Marcelo Caetano. Desbun Filmes; PaleoTV, 2009. 16min, colorido.

PAIVA, A. C. S. Pulsão invocante e constituição de sociabilidades clementes: notas etnográficas sobre karaokê numa sauna em Fortaleza. In: ENCONTRO ANUAL DA ANPOCS, 33., 2009, Caxambú. Anais Eletrônicos... Caxambú, 2009. Disponível em: <http://www. anpocs.org.br/portal/component/option,com_docman/task,cat_view/ gid,88/Itemid,85/limit,15/limitstart,0/order,name/dir,ASC>. Acesso em: 22 out. 2010.

POCAHY, F. A. Marcas do poder: o corpo (do) velho e homossexual nas tramas da hetero e homonormatividade. IN: Fazendo Gênero 8. Florianópolis : Editora Mulheres; UFSC, 2008. Disponível em: $<$ <ttp://www.fazendogenero8.ufsc.br/sts/ST46/Fernando_Pocahy_46.pdf>. Acesso em 17 jan. 2009.

SCOTT, M. WordSmith Tools. Lexical Analysis Software. 2009.

SILVA, L. R. F. Da velhice à terceira idade: o percurso histórico das identidades atreladas ao processo de envelhecimento. História, ciências, saúde-Manguinhos, v.15, n.1, jan-mar, 2008, p. 155-168. Disponível em: <http://www.scielosp.org/pdf/hcsm/v15n1/09.pdf>. Acesso em: 30 mar 2015. 
SILVA, T. S. Irenes: representações sobre homossexuais idosos no contexto midiático sob a perspectiva sistêmico-funcional. 2012. 223f. Dissertação (Mestrado em Letras) - Universidade Federal de Santa Maria, Santa Maria, 2012.

THOMPSON, G. Introducing Functional Grammar. $2^{\text {nd }}$ Edition.

Thiago Santos da Silva

Cristiane

Fuzer London: Hodder Arnold, 2004.

THOMPSON, J. B. A mídia e a modernidade: uma teoria social da mídia. Tradução de Wagner de Oliveira Brandão e Leonardo Avritzer. Petrópolis: Vozes, 1998.

118 VAN LEEUWEN, T. A representação dos actores sociais. In: PEDRO, E.R. (Org.). Análise Crítica do Discurso. Lisboa: Caminho, 1997. p. 169-222.

WEBSTER, J. J. An Introduction to Continuum Companion to Systemic Functional Linguistics. In: HALLIDAY, M. A. K.; WEBSTER, J. J.Continuum Companion to Systemic Functional Linguistics. New York: Continuum, 2009. 